\title{
HELOPHORUS AQUATICUS L. IN AMERICA
}

\section{By P. J. Darlington Jr.}

Helophorus aquaticus L., of which $H$. grandis III. is cited as a synonym, is a common and wide-spread species in Europe, but is apparently not recorded from North America. A single specimen of the species, however, was taken in a mossy puddle beside the upper and smaller of the Eagle Lakes on the shoulder of Mt. Lafayette, N. H., at about $4100 \mathrm{ft}$. elevation. The insect was taken on Apr. 20, 1927, which was said at Boston to be the warmest April day in the history of the weather bureau. The so-called "Lakes" were almost entirely frozen over and contained no visible insect life, but the flood pools were warmed by the sun and yielded over a dozen species of aquatic beetles. The fauna of these Lakes, as determined by a collection made in Sept. 1926, is similar to that of the high, exposed pools of the Presidential Range about twenty-five miles to the north and includes such arctic species as Ilybius discedens Shp. and Colymbetes longulus Lec. The presence in large numbers of Hydroporus badiellus Fall, which is dominant in the Eagle Lakes but apparently absent on the Presidentials, indicates some difference, however.

In our funa Helophorus aquaticus is comparable in size only with $H$. fortis Lec. and very large specimens of $H$. oblongus Lec., from both of which it differs conspicuously by having the pronotal disk, except the depressions, densely and coarsely granulate, each granule having a median puncture. It is also duller, broader, with larger and shallower punctures on the elytral striæ and flatter elytral intervals. It differs from all the species of the genus in the Leconte collection, and I think from all our other North American species, by having a row of large punctures between the first and second elytral striæ near the base.

The New Hampshire specimen is $7 \mathrm{~mm}$. long and has the pronotum green or coppery where it is not obscured. It has been compared with a series in the Museum of Comparative Zoology Cambridge labeled "Germany" and "Austria," and determined as $H$. grandis III., with which it seems to be specifically identical. It answers perfectly to the description of $H$. aquaticus $\mathrm{L}$. in 
Fowler's "British Coleoptera," and there seems to be nothing with which it could well be confused. Fowler gives the length of the species as $5 .-7 \mathrm{~mm}$., and states that the pronotum varies from green to bronze and that the species is common throughout the kingdom.

- More recently I have seen four American specimens of the species in the collections of the Boston Society of Natural History and of Mr. C. A. Frost. The former contained two specimens taken by Professor H. M. Parshley at Orono, Me., Apr. 24 and 13 respectively; the latter, two from Orono, Me., May 3, and Penobsquis, N. B., July 23, the second taken by Mr. Frost. The species is well distributed and probably native, but apparently rare. 

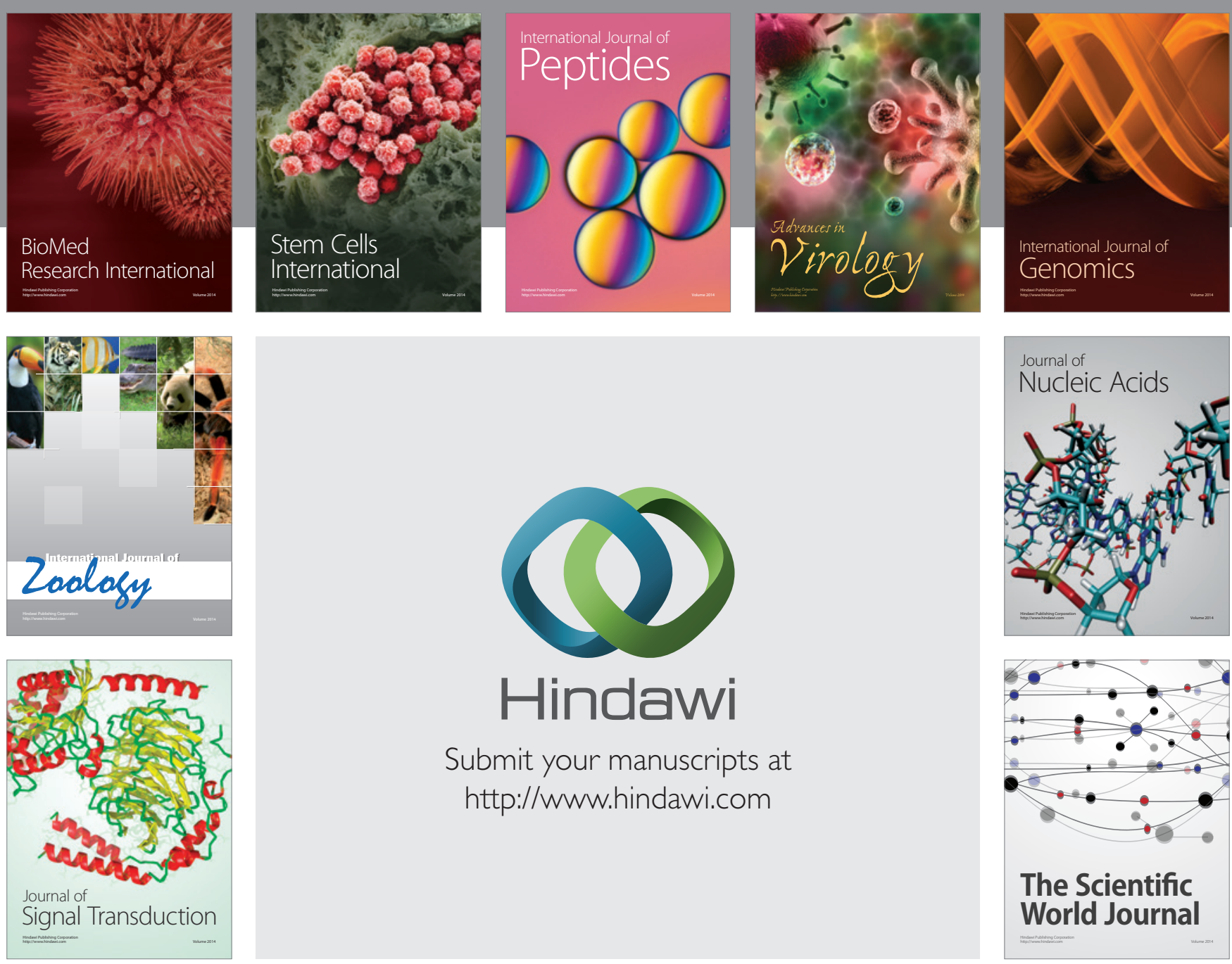

Submit your manuscripts at

http://www.hindawi.com
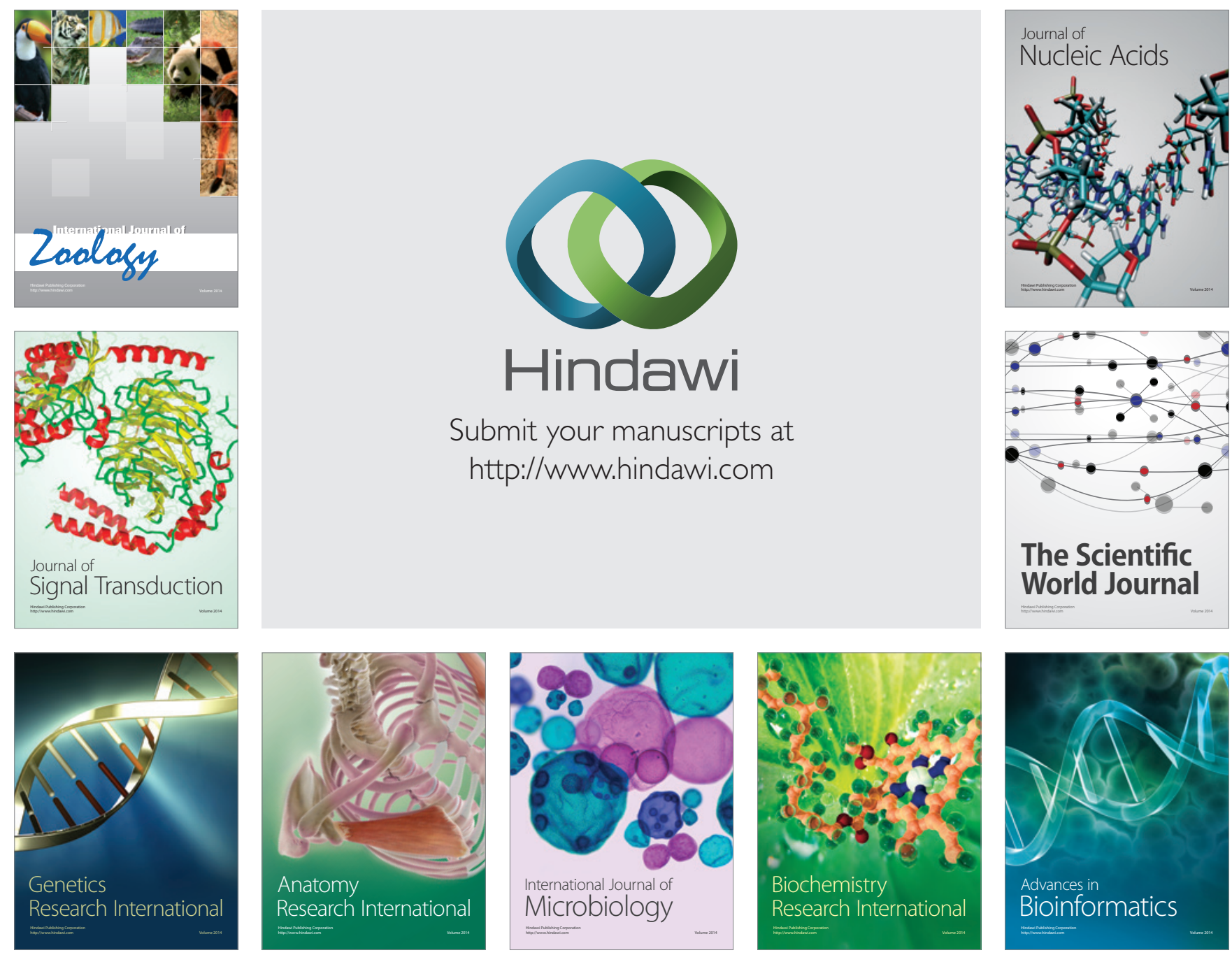

The Scientific World Journal
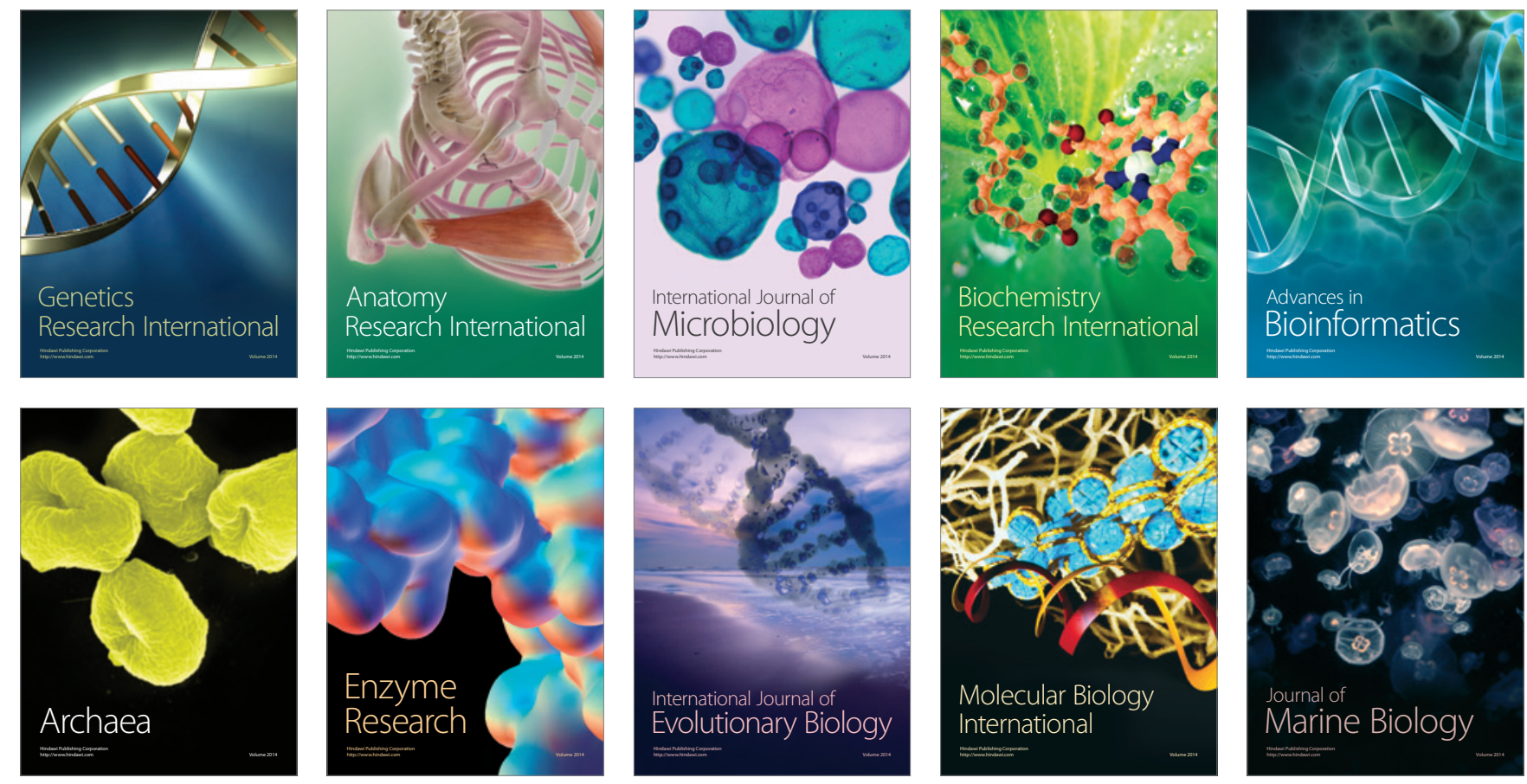